\title{
QUANDO A CRIANÇA NÃO CABE NA LINHA: A PSICOMOTRICIDADE NO PROCESSO DE ALFABETIZAÇÃO E LETRAMENTO' ${ }^{1}$
}

\author{
LÍDIA MARIA DE LIMA \\ Psicopedagoga pela Universidade Metodista de São Paulo. Jornalista. \\ Teóloga. Pedagoga. Mestre em Ciências da Religião pela UMESP.
}

\section{LUCIAN DA SILVA BARROS ${ }^{2}$}

Psicólogo. Mestre em Educação pela USCS. Professor do curso de Psicopedagogia da Universidade Metodista de São Paulo.

\section{RESUMO}

O presente artigo discute a importância da psicomotricidade nos processos de alfabetização e letramento. Busca salientar o valor do movimento, do afeto, da autoconfiança e da autonomia da criança na escolarização, assim como também o papel dos educadores e da família, enquanto facilitadores no desenvolvimento infantil. Para a elaboração da pesquisa, fez-se uso do método história de vida, somando experiências no campo da educação, no processo de alfabetização de crianças do primeiro ano do Ensino Fundamental, assim como também vivências pessoais. A experiência de vida foi somada às pesquisas bibliográficas que colaboraram para os resultados apresentados aqui. Concluiu-se que movimentar-se, expressar-se, sentir e sentir-se, perceber-se como um ser holístico que possui corpo e mente, são elementos fundamentais para o desenvolvimento de qualquer ser humano,

\footnotetext{
1 Este artigo nasce das inquietações da primeira autora, relatando neste texto suas experiências no campo da educação e da alfabetização de crianças, assim como também suas vivências da maternidade. Constitui-se como um material documental produzindo uma narrativa de vida, como mãe e educadora. Para realização das análises e reflexões contou com a colaboração do segundo autor, o qual pôde auxiliar também na própria ressignificação destas experiências e vivências pessoais. Foi o Trabalho de Conclusão de Curso de Psicopedagogia, em 2019.

2 Orientador do trabalho.
} 
logo, a psicomotricidade tem papel essencial no processo de alfabetização e letramento. Além disso, a valorização desta ciência colabora para a transição da criança da Educação Infantil para o Ensino Fundamental, contribuindo com ações preventivas em casos de dificuldades de aprendizagem.

Palavras-chave: Psicomotricidade. Alfabetização. Afetividade.

\begin{abstract}
This article discusses the importance of psychomotricity in the processes of literacy and literacy. It seeks to emphasize the value of movement, affection, self-confidence and the child's autonomy in schooling, as well as the role of educators and the family, as assistants, in child development. For the elaboration of the research, the life history method was used, adding experiences in the field of education, in the literacy process of children in the first year of elementary school, as well as personal experiences. The life experience was added to the bibliographic research that contributed to the results presented here. It was concluded that moving, expressing, feeling and feeling, perceiving oneself with a holistic being: having body and mind, are fundamental elements for the development of any human being, therefore, psychomotricity has an essential role in the process of literacy and literacy. In addition, the valorization of this science contributes to the child's transition from Early Childhood Education to Elementary Education, contributing to preventive actions in cases of learning difficulties.
\end{abstract}

Keywords: Psychomotricity. Literacy. Affectivity.

\title{
INTRODUÇÃO
}

A psicomotricidade é área que estuda a integração entre funções motoras e psíquicas, responsáveis pelo processo de desenvolvimento. O desenvolvimento físico e psicológico, em consonância com o desenvolvimento do sistema nervoso, possibilita que crianças realizem cada vez atividades mais complexas, 
alcançando assim, êxito em tudo que fazem. Desta forma, não parece diferente quando falamos dos processos de alfabetização e letramento.

Ler é compreender o mundo, dar sentido e significado às coisas. Neste campo a aprendizagem da língua materna é um aspecto de extrema importância, pois possibilita o desenvolvimento de um pensamento mais complexo e o alcance da autonomia pelo indivíduo. Compreendemos que neste campo, a afetividade também é um elemento que ganha destaque, pois oferece a motivação interna para o aprender. A afetividade é o componente energético e "refere-se ao conjunto de interesses, dos esforços e dos afetos intraindividuais com suas regulações", principalmente nas relações com as pessoas, mas também com os objetos. (SOUZA, 2003, p. 68).

Pular, correr, brincar saltar, sentir, interagir, entre outros, são alguns dos verbos intimamente ligados ao desenvolvimento infantil e que, portanto, fazem parte da rotina escolar das crianças na primeira infância, que vai do nascimento até os seis anos de idade. Neste período, as atividades relacionadas à psicomotricidade aparecem com frequência no planejamento escolar. Entretanto, quando se dá início ao primeiro ano do Ensino fundamental, tais práticas parecem ser esquecidas.

O caderno e as cartilhas de alfabetização tornam-se o centro das atividades e limitam a criatividade de docentes e crianças, que precisam responder ao que parece ser a única demanda e necessidade da escola: alfabetizar! Mas, como realizar este processo levando em conta as necessidades motoras e afetivas que pulsam no corpo das crianças? Como somar corpo e mente neste processo de alfabetização, deixando de lado as "exigências formais" limitadoras do caderno, da escrita na linha, das mesas enfileiradas, das cópias constantes e, vez por outra, sem sentido?

Esta pesquisa nasce das inquietações de uma mãe-pesquisadora, que compreende que o processo de alfabetização pode e deve contar com o recurso da psicomotricidade, como uma 
aliada. Além disto, compreende-se que a afetividade, a autoconfiança e a autonomia são elementos essenciais para que a criança se perceba como protagonista em processo educacional, cabendo aos adultos que estão em volta, docentes, familiares e equipe pedagógica, atuarem como facilitadores deste processo.

Para organizar esta pesquisa, fizemos uso de uma narrativa dos primeiros dias de aula de uma criança no Ensino Fundamental, em diálogo com a revisão bibliográfica sobre a temática de psicomotricidade no processo de alfabetização. Recorremos às pesquisas de Nogueira, Carvalho e Pessanha (2007), que discutem a importância de psicomotricidade como elemento preventivo, nos processos de alfabetização; também recorreremos às produções de Ambrósio (2011), Sandri (2010), Oliveira (1992), entre outros.

Para reforçar os resultados e discussões, organizamos este artigo em três seções: o primeiro refere-se ao "engessamento" dos corpos das crianças, diante das exigências e "linhas" do caderno, das linhas e letras; na segunda parte trabalhamos o ato de repetir, como algo que pode ser ressignificado e aliado ao movimento e ao afeto e por fim, ressaltamos a importância da psicomotricidade como algo que nos ajuda a transformar o "erro" e a insegurança em autoconfiança e afeto.

\section{METODOLOGIA}

Para a realização desta pesquisa, fizemos uso de uma discussão motivada por uma experiência da pesquisadora - na prática profissional da educação, da alfabetização e do exercício pessoal da maternidade da primeira autora -, o que também ser considerado o método "história de vida", visto que o trabalho tem início com uma narrativa.

A narrativa como processo de reflexão pedagógica permite ao professor, à medida que conta uma determinada situação, compreender causas e consequências de atuação, criar novas 
estratégias num processo de reflexão, investigação e nova reflexão. A narrativa é também um processo de interação com o outro, e nessa medida ajuda-nos a compreender qual o papel de cada um de nós na vida dos outros. (GALVÃO, 2005 , p. 343). A escolha deste método nos aproxima da afetividade e da humanização da pesquisa; temas essenciais para quem discute psicomotricidade e educação. E por que este artigo nasce "em casa", por intermédio das observações e análises de uma "mãe-pesquisadora"? Porque quando discutimos educação, a família é sempre convidada a participar. E o olhar é sempre sobre o outro, ignorando que o pesquisador também sente, interage e vive as mesmas inquietações dos problemas analisados e discutidos no espaço acadêmico.

Além disso, observa-se ainda que:

Na relação pais-filho-ambiente é que a criança poderá construir sua autonomia através do movimento, desenvolvendo-se e preparando-se para a vida. Os pais e o meio têm um papel importante, pois a família é o primeiro agente socializador da criança. Por esse motivo, ela deverá estar bem próxima de seus filhos durante tal processo, estimulando-os, de acordo com suas necessidades e potencialidades, desde as atividades simples às complexas, como sentar, ficar em pé, correr e falar. (AMBRÓSIO, 2011, p. 6).

Se a família é o primeiro espaço de socialização da criança e se é o estímulo materno e paterno que a auxiliará, estimulando as suas potencialidades iniciais e em cada fase de sua vida, o mesmo se dará no processo de escolarização, o que justifica e motiva o desenvolvimento do texto que aqui apresentamos. 


\section{RESULTADOS E DISCUSSÃO}

O exercício da leitura e a escrita são marcos fundamentais na vida escolar de qualquer pessoa; trata-se, praticamente, de um "rito" de passagem, um símbolo de autonomia e de crescimento. Mas, isso, nem sempre acontece de maneira tranquila. Vez por outra, há um abrupto processo de ruptura entre a educação infantil e o início do ensino fundamental. As crianças rompem com as salas coloridas da Educação Infantil, com o parque, as dinâmicas de grupo e os jogos de faz de conta, sempre tão presentes nesta fase da infância - e passam a frequentar um outro espaço de aprendizagem, onde, nem sempre o brincar é a chave para o desenvolvimento, visto que, para muitos/as educadores/ as, a alfabetização é o grande objetivo do primeiro ano do Ensino Fundamental .

Para ilustrar essa experiência, vamos apresentar a seguir um relato pessoal da observação materna, dos primeiros dias de aula de um garoto de 6 anos, no Ensino Fundamental, em uma escola pública:

Ele chegou em casa inquieto. Era a primeira semana na escola nova e no primeiro ano do ensino fundamental. $\mathrm{Na}$ mochila, um estojo com lápis, borracha e apontador, além de um caderno brochura, cheio de linhas e nenhuma ilustração. Na cabeça, alguns receios, muitas expectativas e mundo de imaginação e de possibilidades. No primeiro dia, parecia que tudo tinha ido muito bem, exceto pela notícia de que naquela semana ele começaria a usar o caderno e que ele não poderia ter rabiscos e erros. Era necessário capricho nas letrinhas e cuidado com as linhas. Assim lhe disse a professora. Os próximos dias, daquela semana, foram tensos: ele sentia medo do caderno, falta das brincadeiras e dos desenhos e, com a voz embargada e a testa franzida, me dizia: 'Por que estas linhas precisam ser tão pequenas? E porque a gente repete, sempre, a mesma lição? E se eu errar e a 
borracha borrar? Estou com saudade do infantil' - Disse referindo-se à escola colorida, de educação infantil, onde brincar era o caminho para a aprendizagem. Eu, o abracei e prometi que esse medo passaria e que em breve, aquela lição faria sentido. Faria? (LIMA, 2019, Informação verbal).

A experiência narrada acima, descreve uma cena vivenciada no primeiro semestre de 2019, durante o início do ano letivo desta mãe, que também é educadora e que se viu desafiada a pensar o universo do letramento e da alfabetização, e a importância da psicomotricidade. A angústia gerada pela presença das pautas e a exigência das letras, fortaleciam a ansiedade e fazia sucumbir a possibilidade de celebração da criança, diante de um novo espaço, de uma nova turma e de novas descobertas.

E esta não era uma inquietação isolada. Outras crianças também apresentavam esta insegurança e compartilhavam seus medos em conversas na biblioteca, na fila de entrada e o tema virou pauta da reunião de início do bimestre, uma tentativa acalmar as famílias e naturalizar este processo, enfatizando a alfabetização como "produto final" e "ideal" deste ciclo - ignorando as experiências lúdicas da educação infantil, que valorizavam as brincadeiras, os desenhos livres, as atividades dirigidas, a criatividade e o faz de conta.

Se outrora as crianças desenhavam livremente em folhas sulfites, ou no chão dos pátios escolares, ou em grandes folhas de papéis pardos coletivos e tantas práticas destinadas à educação infantil, ao se deparar com o novo ciclo, no Ensino Fundamental, o que se percebe, em grande parte das escolas públicas, é que os/as alunos/as são apresentados aos livros didáticos, aos cadernos pautados, as grandes lousas. A isso acrescente-se, vez por outra, salas com a arquitetura pouco atraente: cadeiras enfileiradas que exigem um condicionamento de um longo período sentados, com olhares atentos ao docente e com mãos hábeis que começam a traçar as primeiras letras, ainda que sem sentido, mas cumprindo o rito exigido no ambiente escolar. 
Segundo Melissa Probst e Celso Kraemer (2012),

Cada espaço dentro da instituição escolar é previamente pensado para permitir a operacionalização do fazer pedagógico, supostamente destinado apenas à aprendizagem dos conteúdos curriculares, mas o que prioritariamente se efetiva é o aprendizado da obediência, da submissão ritualística do corpo, comportamentos adaptados a determinadas regras sociais. A exigência da disciplina do corpo infantil é visível em qualquer sala de aula. (PROBST \& KRAEMER, 2012, p. 515).

O que se vê é uma preocupação excessiva em "cumprir o conteúdo", criar o hábito de "obedecer" como um caminho para a aprendizagem e para o cumprimento das rotinas estabelecidas para o dia. "Domesticados" em sua cadeira e presos às linhas pautadas de seu caderno, a liberdade de criação, movimento e interação com o seu corpo e o espaço, tornam-se limitados. E o conceito de motricidade, essencial para o desenvolvimento humano, vai sendo esquecido e/ou ignorado.

Segundo Gislene de Campos Oliveira (1992), o termo psicomotricidade apareceu pela primeira em 1920 e mostrava-se como o resultado da soma entre movimento e pensamento. Entretanto, na Grécia Antiga, Aristóteles (20) já ressaltava que a humanidade é composta de corpo e alma, e as duas dimensões deveriam ser valorizadas e estimuladas. Hoje, a Associação Brasileira de Psicomotricidade (SBP) define o tema da seguinte forma:

Psicomotricidade é ciência que tem como objeto de estudo o homem através do seu corpo em movimento e em relação ao seu mundo interno e externo, bem como suas possibilidades de perceber, atuar, agir com o outro, com os objetos e consigo mesmo. Está relacionada ao processo de maturação, onde o corpo é a origem das aquisições cognitivas, 
afetivas e orgânicas, É sustentada por três conhecimentos básicos: o movimento, o intelecto e o afeto. (Associação Brasileira de Psicomotricidade. 2019, on-line).

Observa-se que a ciência que poderia ser utilizada como uma ferramenta auxiliar nas relações pessoais e interpessoais, cognitivas e afetivas, facilitando o processo de interação e aprendizagem, passa a ser dispensável, diante da pauta dos cadernos, das cartilhas e das cópias maçantes do alfabeto, das sílabas e dos numerais. A memorização e o mimetismo passam a ser elementos essenciais, desprezando a possibilidade de criação, interação, mobilidade, movimento e autonomia da criança neste processo. Prioriza-se o desenvolvimento das questões ligadas ao cérebro, ignora-se as necessidades e habilidades do corpo.

Para Gislene de Campos Oliveira (2010) "a psicomotricidade se caracteriza por uma educação que se utiliza do movimento para atingir outras aquisições mais elaboradas, como as intelectuais". (2010, p. 09) Diante disto, torna-se inviável pensar o processo de alfabetização, ignorando a importância do movimento e da interação.

\section{PARA SABER UM POUCO MAIS...}

Nas palavras de Hilda Torres Falcão e Maria Auxiliadora Motta (2009), a "história da psicomotricidade é solidária à história do corpo". Desde a antiguidade, sempre houve esta preocupação com o corpo. Na Grécia Antiga, por exemplo, Platão (428 a.C.-347 a.C.) e Sócrates (470 a.C a 399 a.C.) já manifestavam preocupação com esse tema.

As pesquisadoras destacam que

Para Platão, o primeiro elemento da educação do espírito e do corpo está em alimentá-lo e mexê-lo a cada momento, e já afirmava haver uma separação distinta entre corpo e alma, colocando o corpo apenas como lugar de transição 
da existência no mundo de uma alma imortal. Para Aristóteles o corpo é matéria moldada pela alma. A alma é que põe o corpo em movimento, sendo ela a forma do corpo. Enunciava, assim, um primórdio de pensamento psicomotor quando analisou a função da ginástica para melhorar o desenvolvimento do espírito. (FALCÃO \& BARRETO, 2009, p. 85).

Por essa lógica, cuidar do corpo é um caminho para o desenvolvimento da espiritualidade, e que nos ajuda a trabalhar, também, com os sentimentos e com as habilidades intelectuais.

Torna-se importante dizer ainda, tal como se vê em Esteban Levin, que o termo - psicomotricidade - surge inicialmente com o neurologista francês Duprê:

(...) que, em 1907, a partir de seus estudos clínicos, define a síndrome da debilidade motora, composta de sincinesias (movimentos involuntários que acompanham uma ação), paratomias (incapacidade para relaxar voluntariamente uma musculatura) e inabilidades, sem que lhes sejam atribuídos danos ou lesão extrapiramidal. Ele rompeu com os pressupostos da correspondência biunívoca entre a localização neurológica e perturbações motoras da infância e formulou a noção de psicomotricidade através de uma linha filosófica neurológica, evidenciando o paralelismo psicomotor, ou seja, a associação estreita entre o desenvolvimento da psicomotricidade, inteligência e afetividade. (LEVIN, 2003, p. 24)

Levin afirma que para Dupré, as questões motoras estão intimamente ligadas às inteligências e à afetividade, não podendo, portanto, serem pensadas de maneira fragmentada. Já na área educacional, é o pedagogo e médico Henri Wallon (1879-1962), quem dá visibilidade para a ciência, por intermédio da teoria psicogenética, na qual, segundo Sandra Bazylewski (2015, p. 
12), se vê o "corpo como continente de cognições, afetividade e motricidade".

GRATIOT-ALFANDÉRY chamam atenção para o fato de que

Wallon detalha minuciosamente as origens orgânicas da emotividade, menos para justificar uma visão biologicista e mais para destacar sua maneira de compreender a natureza humana. Para ele, o ser humano é organicamente social. Isso porque estão nessa força da emotividade humana e em seu caráter contagioso e epidêmico as condições para que seja mediada pela cultura, interpretada pelo adulto e promotora, a partir de então, do desenvolvimento cognitivo da criança. Significa dizer que o bebê expressa sua insatisfação por meio do choro, que de início é sua única maneira de relacionar-se. Esse choro mobiliza a mãe e ela o interpreta de acordo com seus valores e significados culturais. A interação entre ambos será responsável pelo desencadeamento das funções cognitivas na criança. Igualmente relevantes e indissociáveis nesse processo são as funções motoras que, no entendimento de Wallon, vão além da tarefa de executar as ações pensadas pelo sujeito. $\mathrm{O}$ ato motor no ser humano garante desde o início a função de expressão da afetividade (por meio dos gestos, expressões faciais e agitação corporal). Essa atividade expressiva, possibilitada pela atividade motora, regula, modula e produz estados emocionais. (GRATIOT-ALFANDÉRY, 2010, p. 37).

Observa-se, assim, que desde o nascimento a motricidade da criança está intimamente relacionada com o seu desenvolvimento e que a junção de ambos, associada ao meio, fará com que a criança se desenvolva de maneira integral. Observar as funções motoras da criança e relacionar-se afetivamente com ela, é a forma de manter a comunicação entre ela e os adultos 
que estão ao seu redor. No mais, durante toda a vida da criança essa temática será fundamental e ganhará outros contornos e espaços, inclusive na alfabetização, tal como veremos a seguir.

\section{CADERNOS PAUTADOS E CORPOS ENGESSADOS: SERÁ QUE ISTO É MESMO NECESSÁRIO?}

"Por que as linhas são tão pequenas?" - a linha do caderno parece ser um limitador para a criança, que até então estava acostumada ao espaço, à possibilidade de criar seus próprios desenhos e que ainda não tinha a obrigação de ser "análoga" ao real, e muito menos de estar associada à formalidade do mundo das letras, palavras e linhas. Neste sentido, como bem reafirma Ana Paula F. Kamila e et al (2010), é por meio das brincadeiras, dos jogos e do movimento que a criança se conhece, se desenvolve e socializa-se, e assim, explora o mundo, descobre-se, entende-se e expressa sentimentos e reações.

O problema é que no espaço do Ensino Fundamental, essa disposição e interação ganham outros contornos e pautas limitadoras:

(...) no Ensino Fundamental, há filas para entrar, carteiras alinhadas, nucas atrás de nucas, mesinhas de quatro a seis lugares, onde apenas a proximidade física une as crianças. Não há cooperação, expressão de necessidades individuais e coletivas. Prevalecem atividades iguais para todas as crianças, contrariando as propostas de autonomia, expressão e identidade infantis. (KISHIMOTO, 2001, p 8).

Tudo parece colaborar para este "engessamento" da criança: o caderno, a linha, a fila, a cadeira, a mesinha... itens que podem ajudar para que este processo desperte a ansiedade, a competitividade, e até mesmo a insegurança da criança diante desta nova etapa do processo escolar.

Este tipo de disposição da sala de aula, segundo o senso comum, visa manter uma organização e disciplina que colabore 
com o desenvolvimento intelectual das crianças, mas, enquanto valorizamos o desenvolvimento da mente, torna-se mesmo necessário o "engessamento" do corpo? Será que é importante anular o movimento para desenvolver o intelecto? Segundo J. B. Freire (1997), corpo e mente precisam encontrar espaços nas salas de aula:

Corpo e mente devem ser entendidos como componentes que integram um único organismo. Ambos devem ter assento na escola, não um (a mente) para aprender e o outro (o corpo) para transportar. É necessário, a cada início de ano, que o corpo da criança também seja matriculado na escola, e não seja considerado por algumas pessoas como um 'estorvo', que quanto mais quieto estiver, menos atrapalhará a aprendizagem. (FREIRE, 1997, p.14).

Parece difícil, para alguns educadores/as, compreender a necessidade de unir corpo e mente no processo de desenvolvimento, sendo inviável exigir das crianças uma postura tão rígida, como se este fosse o único caminho para o "sucesso" em seu processo de aprendizagem.

Fazendo uma analogia com o espaço da sala de aula, é no corpo que serão impressas e expressas as letras e palavras que irão compor as primeiras "histórias" deste "livro", que é a vida escolar. Para Marina de Souza Costa e Daniele Nunes Silva (2012, p.59) é no corpo que a vivência criativa se manifesta, e isto o torna suporte central da mediação das práticas de leituras e escritas realizadas pela criança.

Quando a criança tem consciência corporal, ou seja, conhece as dimensões de seu corpo, sabe se organizar, desenvolve equilíbrio, conhece e interage bem com os espaços e com os objetos e pessoas que estão ao redor; certamente apresentará menos dificuldades no processo de alfabetização. Logo, saberá lidar bem com as "linhas", ainda que estas sejam pequeninas. 


\section{E POR QUE A GENTE REPETE? E O QUE A GENTE REPETE?}

Observa-se nestes primeiros meses do Ensino Fundamental, que a criança, vez por outra, é convidada a repetir: a grafia das letras em ordem alfabética, de numerais, até que aprenda o contorno a associação com quantidade, do "cabeçalho" onde se vê o nome da escola, a data, o nome do aluno e da professora - ainda que isto não faça muito sentido para a criança. Esta foi uma das reclamações feita pela criança e narrada no início deste artigo ("e porque a gente repete sempre a mesma lição?").

Isto nos faz pensar nas brincadeiras de roda, nas atividades de percurso realizadas na educação infantil, nos jogos de amarelinha, ou com bolas, petecas e bambolês, nos desenhos, nas atividades com massinha e sucata, entre outras, que também se faziam presentes na rotina da escola, e que se repetiam constantemente, mas, não encaradas como "atividades", "lições" ou "exigências". A forma prazerosa e divertida como a rotina se desenvolvia, fazia com que a criança não percebesse que ali já havia uma repetição de gestos e exercícios que faziam parte do planejamento docente, para o seu desenvolvimento psicomotor. E aqui a diferença está no sentido e no valor depositado por docentes e crianças diante da atividade proposta:

A repetição, requerida pelas demandas de assimilação funcional dos esquemas de ação, tem por consequência algo muito importante para o desenvolvimento da criança: a formação de hábitos. Nesse sentido, os jogos de exercício são formas de, por seu prazer funcional, repetir, por exemplo, uma sequência motora e, por isso, formar um hábito. (MACEDO, 1995, p. 6).

É nesta prática de repetir, de maneira prazerosa e lúdica, que a criança vai assimilando os conceitos que irão colaborar com o seu processo de desenvolvimento psicomotor para que, 
futuramente, possa experimentar também o processo de acomodação do conhecimento. Mas, no processo de leitura e escrita, será que a repetição também é um exercício válido? Sim, desde que haja sentido naquilo que está sendo proposto.

É possível repetir, interagir e brincar com as atividades. Trazer a ludicidade e o movimento para aquilo que se deseja ensinar. Liane Zanella (1997, p. 27) afirma que a repetição é um recurso comum no processo de aprendizagem e que alguns comportamentos humanos são aprendidos por repetição, especialmente aqueles que exigem treino motor e memorização, tal como se vê no exercício da escrita e da leitura.

O uso do caderno, do lápis, o registro das letras, das palavras que se repetem, da rotina, do nome... exercícios comuns no processo de alfabetização. Mas, é importante pensar no sentido destas atividades, e como a criança percebe tal sentido. Muito mais do que a técnica (a escrita como um exercício motor), pelo processo de letramento, a criança precisa entender a função da escrita e da leitura em seu cotidiano, como atividades prazerosas e que tem função social: ajuda a pensar, a interagir, a se informar, a relacionar-se com o grupo, etc.

E se a repetição estivesse atrelada ao universo lúdico? Não seria interessante, por exemplo, reproduzir as letras do nome ou do alfabeto com argila, ou massinha? Uma atividade que, vez por outra, é utilizada para "ocupar" o tempo da criança, mas que, quando direcionada, colabora com a coordenação motora fina, com a concentração, com a oralidade e tantos elementos, que auxiliam na alfabetização. E se a brincadeira envolvesse jogos de memória, com letras e/ou números, já que a ideia é repetir e rememorar? Será que a escrita ou a leitura perdem o sentido se estiverem fora do espaço delimitado e das repetições exigidas?

Por meio de uma aula lúdica, o aluno é estimulado a desenvolver sua criatividade e não a produtividade, sendo sujeito do processo pedagógico. Por meio da brincadeira o 
aluno desperta o desejo do saber, a vontade de participar e a alegria da conquista. Quando a criança percebe que existe uma sistematização na proposta de uma atividade dinâmica e lúdica, a brincadeira passa a ser interessante e a concentração do aluno fica maior, assimilando os conteúdos com mais facilidades e naturalidade. (KISHIMOTO, 1994, p.49).

Aulas lúdicas, tal como nos propõe a citação acima, colaboram para o protagonismo da criança e para a sua autonomia neste processo de aprendizagem. Assim, repetir por prazer; porque é parte da brincadeira, do universo que é próprio da infância. Assim é porque desperta a curiosidade, a reciprocidade e a imaginação podem ser caminhos para a naturalização deste processo que é contínuo e que não é igual, nem linear, visto que cada um aprende no seu tempo e no seu ritmo. Repetindo o que lhe parece necessário e prazeroso, até que a criança se sinta à vontade para interagir com os cadernos pautados.

\section{“E SE EU ERRAR?" - A INSEGURANÇA QUE A GENTE TRANSFORMA EM CONFIANÇA E AFETIVIDADE}

O medo de errar diante das letras, da escrita e das leituras apresenta-se com muita frequência entre as crianças do primeiro ano do Ensino Fundamental. $\mathrm{O}$ erro parece deixar marcas não só nas páginas do caderno, mas no corpo desta criança, que ainda não se sente confiante diante desta fase da escolarização. E mais uma vez, a psicomotricidade mostra-se como um caminho para o desenvolvimento da confiança e da autonomia:

Motricidade e aprendizagem constituem um binômio inseparável, porque é por meio do corpo que a criança aprende a relacionar-se e conviver com o diferente. Aprendizagem que nasce do desejo e não só da lógica do dever; que gera relações de confiança e segurança necessárias às aquisições a 
nível cognitivo e sócio-afetivo; que tornam os alunos atores do próprio processo de desenvolvimento na construção do saber cada vez mais integrado e significativo. (CARVALHO et al, 2013, p.75).

Relação de confiança e segurança, pessoal e relacional, elementos fundamentais para o desenvolvimento cognitivo. E é acreditando nesta proposta relacional e socioafetiva, que a psicomotricidade soma o corpo, a mente e o afeto, respeitando o ser humano, de maneira integral.

Além disto, a proposta da psicomotricidade também está aliada com a função da psicopedagogia: uma ação preventiva, mediadora e terapêutica, que facilita os processos de aquisição de conhecimento e apresenta possibilidades criativas para auxiliar as crianças, de acordo com a sua faixa etária e com os anseios, receios e/ dificuldades de aprendizagem.

Outro elemento importante na narrativa utilizada nesta pesquisa, refere-se ao erro, algo inerente ao processo de aprendizagem. Se pensarmos na escola como um grande espaço de "experienciar", o erro deveria ser visto como uma "hipótese" da criança:

(...) o erro deve ser encarado como resultado de uma postura de experimentação, onde a criança levanta hipótese, planeja uma estratégia de ação e a põe à prova. Cabe ao professor ajudar seus alunos a analisarem a adequação do procedimento selecionado, encaminhando-os na busca de condutas mais ricas, complexas e diversificadas. (DAVIS et al, 1991, p.205).

É o olhar atento de docentes, da equipe pedagógica e da família que deve colaborar para que o erro não se transforme em um ato "bloqueador", capaz de interromper seus avanços e descobertas. Mas, se optarmos por uma prática pedagógica que 
valoriza as tentativas, que desperta a autoconfiança e que compreenda as emoções envolvidas no processo de aprendizagem, certamente teremos crianças mais dispostas a estar no espaço escolar, sem medo, sem culpa e vivenciando uma aprendizagem de descobertas constantes. Experimentando a "boniteza" e “alegria" ditas por Paulo Freire (1996, p. 161), referindo-se ao ensinar e o aprender.

É importante destacar também que este medo do erro, vez por outra, nasce, não só da insegurança da criança, mas também da etapa de desenvolvimento em que ela se encontra. Neste caso, então, cabe ao adulto, facilitador da aprendizagem, acompanhar e conduzir as crianças com afeto, respeito e confiança, elementos essências em uma educação que valoriza a psicomotricidade:

(...) o professor deve estar sempre atento às etapas do desenvolvimento do aluno, colocando-se na posição de facilitador da aprendizagem e calcando seu trabalho no respeito mútuo, na confiança e no afeto. Ele deverá estabelecer com seus alunos uma relação de ajuda, atento para as atitudes de quem ajuda e para a percepção de quem é ajudado. (TAVARES, 2017, et al, s/p.).

Quando docentes apontam o erro, ou "cobram" acertos, criam entre as crianças uma atmosfera de competição e uma relação de "punição" como consequência do erro, o que pode afastar a criança de uma relação proximal e afetiva com o docente, despertando na mesma um sentimento de "fracasso" ou a ausência da confiança.

Gislene de Campos Oliveira (1992), afirma que:

Todo movimento realiza-se sobre um fundo tônico e um dos aspectos fundamentais é sua ligação com as emoções. A boa evolução da afetividade é expressa através da postura, de atitudes e comportamentos. Podemos transmitir, 
sem palavras, através da linguagem corporal, todo o nosso estado interior. Transmitimos a dor, o medo, a alegria, a tristeza e até o nosso conceito de nós mesmos. Uma criança, por exemplo, que não acredita muito em si tem a tendência de se "envolver", isto é, de manter seu corpo em estado de tensão quando se sente ameaçada. (OLIVEIRA, 1992, p. 29).

Assim, em uma reação ao medo, teremos, possivelmente, uma criança que se retrai, num ato de autodefesa, e que, talvez, por conta desta postura, possa desenvolver dificuldades em seu processo de alfabetização. Se sabemos que o afeto e autoconfiança são um caminho, por que insistir nas "rígidas linhas e pautas", para cumprir ritos e exigir cadernos "perfeitos", sem "erros", mas sem demonstrar a devida preocupação com as marcas e "borrões" gerados pela falta de afeto e autoconfiança?

"E se eu errar?" - no exercício da maternidade/maternagem a mãe acolhe a criança com um abraço e com palavras de incentivo, para que ele retome a sua autoconfiança e prossiga com as tentativas de leitura e escrita. Como pesquisadora e educadora, em parceria e diálogo com a escola, foi possível observar a criação e a implementação de práticas extraclasses de leituras, jogos cooperativos, musicalização e parcerias multidisciplinares que passaram a envolver a criança de maneira holística, tal como nos propõe a prática da psicomotricidade.

Outras práticas também se tornaram evidentes: não houve mais o "exigir" do registro "perfeito" no caderno pautado, mas houve a proposta de "experiências", que envolveu muito mais as crianças, de maneira mais afetiva, mais viva e participativa, muito mais significativa e muito além das linhas do caderno. Incluindo, por exemplo, a prática de explorar os arredores da escola e transformar o terreno em declive em um grande "tobogã natural", onde as crianças transformavam suas caixas de papelão em um "meio de transporte" divertido, que lhes permitia 
ter noção de espaço, equilíbrio, cooperação e diversão. Outras linhas, outros traços, além do caderno, do lápis e das carteiras. Uma educação com efeito e afeto.

\section{CONSIDERAÇÕES FINAIS}

Este artigo buscou compreender o papel da psicomotricidade e, por consequência, da afetividade, no processo de alfabetização. Para isso fizemos uso do método de história de vida, unindo nestas discussões, experiências profissionais e pessoais, a fim de se chegar à construção de uma narrativa.

Após as reflexões e observações realizadas, foi possível concluir que movimentar-se, expressar-se, sentir e se sentir, perceber-se com um ser holístico que possui corpo e mente, são elementos fundamentais para o desenvolvimento de qualquer ser humano. Logo, a psicomotricidade tem papel essencial no processo de alfabetização e letramento. Além disso, a valorização desta ciência colabora para a transição da criança da Educação Infantil para o Ensino Fundamental, contribuindo com ações preventivas em casos de dificuldades de aprendizagem.

Durante as observações feitas neste processo de alfabetização e letramento, foi possível perceber o quanto o apoio da família, o vínculo, o incentivo ao movimento e a afetividade foram essenciais para que a criança se aventurasse no universo da leitura e da escrita. Descobrir as primeiras palavras, realizar, com autonomia, a leitura de gibis e de seus contos favoritos, desenhar no chão do quintal o seu próprio nome, ou o nome das pessoas da família, delimitando os espaços para as brincadeiras ou para a organização dos brinquedos; caminhar até a escola identificando os nomes dos estabelecimentos comerciais e as placas com os nomes e números das ruas e das casas. Tudo isso foi essencial para esse processo.

Conforme avançamos, chegando à fase de composição de frases, leitura de receitas e escrita de bilhetes. Percebemos o quanto a autonomia e a autoconfiança foram se tornando cada 
vez mais evidentes. Aos poucos, o medo de errar foi desaparecendo, dando espaço para a "expectativa" diante do desafio e da alegria de superar o que lhe parecia assustador.

O processo ganhou sentido e significado. Ler, para adentrar no universo de seus heróis favoritos; para localiza-se nas ruas do bairro; para entender as mensagens da internet, ou para pesquisar suas músicas favoritas nas plataformas digitais. Escrever: para criar roteiros para as histórias que imagina viver com a irmã mais nova e com os amigos da escola; para deixar registrada sua lista de "compras" antes da feira no domingo, garantindo assim as frutas e o pastel favorito; para deixar bilhetes para quem gosta, tal como fez, ao se despedir de familiares queridos.

Ler e escrever com o corpo. Dizer o que sente, com ou sem palavras. Fazer uso destas ferramentas para interagir com outros grupos, para socializar-se. Para se ver, para ser e estar. Não se trata de um processo fácil, nem tampouco solitário. Exige trocas que extrapolam as linhas, os combinados e a formalidade da obediência e da rigidez dos corpos. É contínuo, progressivo e constante. É movimento de corpo e mente: é psicomotricidade.

\section{REFERÊNCIAS}

AMBRÓSIO, Marcela Fernanda de Souza et al. A psicomotricidade e alfabetização de alunos do $2^{\circ}$ ano do ensino fundamental. 2011.

BAZYLEWSKI, Sandra et al. Um olhar pedagógico para a dimensão motora: contribuições de Henri Wallon. 2015.

CARVALHO, Luzia Alves; WAGNER, Liliana Azevedo Nogueira; QUITETE, Tatiana Moço Carvalho. O corpo e o universo lúdico no desenvolvimento de habilidades essenciais no processo de letramento e alfabetização. Humanas Sociais \& Aplicadas, v. 3, n. 7, 2013.

DAVIS, Cláudia; ESPOSITO, Yara Lúcia. O papel e a função do erro na avaliação escolar. Revista Brasileira de Estudos Pedagógicos, v. 72, n. 171, 1991.

FALCÃO, Hilda Torres; BARRETO, Maria Auxiliadora Motta. Breve histórico da psicomotricidade. Ensino, Saúde e Ambiente Backup, v. 2, n. 2, 2009.

FREIRE, J. B. Educação de corpo inteiro: teoria e prática da Educação Física. São Paulo: Scipione, 1997.

FREIRE, Paulo. Pedagogia da autonomia: saberes necessários à prática educativa. São Paulo: Paz e Terra, 1996. 
GALV ÃO, Cecília. Narrativas em educação. Ciência \& Educação (Bauru), v. 11, n. 2, p. 327-345, 2005.

GRATIOT-ALFANDÉRY, Hélène. Henri Wallon. Tradução e organização: Patrícia Junqueira. Recife: Fundação Joaquim Nabuco, Editora Massangana, 2010. (Coleção Educadores).

KAMILA, Ana Paula Folador et al. A estimulação psicomotora na aprendizagem infantil. 2010.

KISHIMOTO, Tizuko Morchida. A LDB e as instituições de educação infantil: desafios e perspectivas. Revista Paulista de Educação Física, p. 07-14, 2001. . Tižko Morchida. O jogo e a educação infantil. São Paulo: Livraria Pioneira Editora, 1994.

LEVIN, Esteban. A clínica psicomotora: a linguagem do corpo. In: A clínica psicomotora: a linguagem do corpo. 2003. p. 341-341.

LIMA, Lídia Maria de. (Diálogo com Pedro Lima Bastos), 2019. Informação verbal.

MACEDO, Lino. Os jogos e sua importância na escola. Cadernos de pesquisa, n. 93, p. 5-11, 1995. Disponível em: https://dialnet.unirioja.es/servlet/ articulo? codigo $=6209194$ Acesso em 29/10/2019.

NOGUEIRA, Liliana Azevedo; DE CARVALHO, Luzia Alves; PESSANHA, Fernanda Campos Lima. A psicomotricidade na prevenção das dificuldades no processo de alfabetização e letramento. Perspectivas OnLine 2007-2011, v. 1, n. 2, 2007.

OLIVEIRA DINIZ, Lucas Desidério et al. Arquitetura escolar-ensino fundamental padrão popular. Anais do VII universo ateneu, p. 335.

Disponível em: http://www.uniateneu.edu.br/documentos/universo-ateneu/ vii-anais-do-universo-ateneu-2018-volume1-messejana-e-lagoa.pdf\#page $=336$. Acesso em 16/10/2019.

OLIVEIRA, Gislene de Campos. Psicomotricidade: um estudo em escolares com dificuldades em leitura e escrita. 1992. [371] f. Tese (doutorado) Universidade Estadual de Campinas, Faculdade de Educação, Campinas, SP. Disponível em: < http://www.repositorio.unicamp.br/handle/REPOSIP/253637>. - (2010). Psicomotricidade: educação e reeducação num enfoque psicopedagógico (12 ed.). Petrópolis, RJ: Vozes.

PROBST, Melissa; KRAEMER, Celso. Sentado e quieto: o lugar do corpo na escola. Atos de Pesquisa em Educação, v. 7, n. 2, p. 507-519, 2012. Disponível em: https://gorila.furb.br/ojs/index.php/atosdepesquisa/article/view/3163

SANDRI, Lorena da Silva Lemos. A psicomotricidade e seus benefícios. Revista de educação do IDEAU, v. 5, n. 12, p. 1-15, 2010. Disponível em: https:/ / mid.curitiba. pr.gov.br/2015/00162762.pdf

SOUZA COSTA, Teixeira Mendes; SILVA, Daniele Nunes Henrique. O corpo que escreve: considerações conceituais sobre aquisição da escrita. Psicologia em Estudo, v. 17, n. 1, p. 55-62, 2012.

SOUZA, Maria Thereza Costa Coelho de. O desenvolvimento afetivo segundo Piaget. In Afetividade na escola: alternativas teóricas e práticas. ARANTES, 
Valéria Amorim (org). São Paulo: Summus editorial. p. 53-70, 2003.

TAVARES, Sandra Ferreira. O brincar na educação infantil: uma comunicação com a psicomotricidade. 2017. Disponível em: https://editorarealize. com.br/revistas/conedu/trabalhos/TRABALHO_EV073_MD1_SA9_ ID6829_16102017001256.pdf. Acesso em 03/11/2019.

ZANELLA, Liane. Aprendizagem: uma introdução. In LA ROSA, Jorge. Psicologia e Educação: o significado do aprender. 6. ed. Porto Alegre. PUCRS, 2003.

\section{Site Consultado:}

Associação Brasileira de Psicomotricidade. 2019. Disponível em: https:// psicomotricidade.com.br/sobre/o-que-e-psicomotricidade/; Acesso em 03/11/2019. 